\title{
Doğu Ege Denizi Türkiye Kıyılarında Varlığı Bilinen veya Düșünülen Deniz İçi Termal Çıktılar Çevresinde Gözlenen Bentik Foraminifer Topluluklarında Belirlenen Değișimler ve Etkenler
}

\author{
Variations and Factors Affecting the Benthic Foraminifer Assemblages \\ Around the Submarine Springs Which are Known/Suggested to Be \\ Present on the Eastern Aegean Coasts of Turkey
}

\author{
ENGIN MERIÇ ${ }^{1}$, IPEK F. BARUT ${ }^{2}$, M. BAKI YOKEŞ ${ }^{* 3}$, MUSTAFA ERYILMAZ ${ }^{4}$, \\ FULYA YÜCESOY-ERYILMAZ ${ }^{4}$, FEYZA DINÇER ${ }^{5}$ \\ ${ }^{1}$ Moda Hüseyin Bey Sokak No: 15/4, 34710 Kadıköy, İstanbul \\ 2 İstanbul Üniversitesi, Deniz Bilimleri ve İșletmeciliği Enstitüsü 34134 Vefa, İstanbul \\ ${ }^{3}$ AMBRD Doğa Bilimleri, Hanımefendi Sokak No:160/6 34384 Șișli İstanbul \\ ${ }^{4}$ Mersin Üniversitesi, Mühendislik Fakültesi, Jeoloji Mühendisliği Bölümü, 33343 Çiftlikköy, Mersin \\ ${ }^{5}$ Nevșehir Üniversitesi, Mühendislik ve Mimarlık Fakültesi, Jeoloji Mühendisliği Bölümü 50300 Nevșehir \\ Geliș (received) : 17 Ağustos (August) 2018 \\ Kabul (accepted) : 23 Kasım (November) 2018
}

öz

Doğu Ege Denizi (Türkiye) ve Midilli Adası (Yunanistan) kıyılarında belirlenmiș olan veya belirli noktalarda foraminifer topluluklarının sunduğu renklenme, yabancı foraminiferlerin varlığı ve șekil bozukluğu gibi farklı özellikleri nedeniyle varlığı düșünülen sıcak su çıkıtıarı çevresinde yapılmıș olan araștırmalarda Coscinospira hemphrichii, Euthymonacha polita, Peneroplis pertusus, P. planatus, Amphisorus hemprichii, Sorites orbiculus, S. variabilis, Cymbaloporetta plana, C. squammosa ve Amphistegina lessonii, A. lobifera gibi yabancı bentik foraminiferlerin yayılımında büyük farklılıkların olduğu gözlenmiștir. Kușadası Körfezi sıcak su çıktısı etrafında gözlenen foraminifer topluluğu oldukça zengin denilebilecek yabancı cins ve türlere sahiptir. Doğanbey Körfezi topluluğu ise bu özellik açısından fazla zengin değildir. Karaburun Yarımadası, llıca Koyu'nda ise farklı bir durum ile karșılașılmıștır. Yabancı topluluğu içinde Ege Denizi için karakteristik bir foraminifer olan Amphistegina lobifera yoktur. Buna karșın Karaburun Yarımadası kuzeybatısından alınmıș olan güncel çökel örnekleri bol denilebilecek sayıda Amphistegina lobifera içermektedir. Daha kuzey alanda Aliağa çevresindeki llıca Burnu'nda birbirine yakın iki noktada $40^{\circ} \mathrm{C}$ ve $51^{\circ} \mathrm{C}$ sıcak su çıktısı bulunmaktadır. Alınmıș olan 13 örnekte Amphistegina lobifera dıșında Peneroplis pertusus, P. planatus, Amphisorus hemprichii ve Sorites orbiculus gibi Ege Denizi için karakteristik olan cins ve türlere ait herhangi bir bireye rastlanılmamıștır.

Elde edilen bulgular ile daha önce çalıșıımıș olan Kușadası, Doğanbey, Karaburun Yarımadası kuzeybatısı gibi alanlarda varılan sonuçlar karșılaștııılı̆ğında büyük bir farkın varlığı ortaya çıkmaktadır. Adı geçen üç bölgede gözlenmiș olan Peneroplis pertusus, P. planatus, Coscinospira hemprichii, Sorites orbiculus ve Amphistegina lobifera bireylerine Aliağa örneklerinde rastlanılmamıștır. Bu durum Ege Denizi'ndeki bazı noktalarda çok farklı ekolojik koșulların varlığı veya eksikliği nedeniyle gerçekleșmiș olabilir. Örnek olarak Çeșme llıca Koyu gösterilebilir. Burada $28.4^{\circ} \mathrm{C}$ sıcak su çıktısının varlı̆ı̆na karșın Amphistegina lobifera dıșında yukarıda adı geçen diğer bentik foraminiferler bulunmuștur. Hâlbuki Kușadası Körfezi, llıca Koyu ve Karaburun Yarımadası KB'da oldukça fazla sayıda denilebilecek güney Pasifik ve Kızıldeniz kökenli Euthomonacha polita ile Coscinospira acicularis bireylerine rastlanılıș̦tır. Aliağa llıca Burnu'ndaki $51^{\circ} \mathrm{C}$ ve $40^{\circ} \mathrm{C}$ sıcaklık sunan 2 sıcak su kaynağı çevresinde ise adı geçen 5 bentik foraminifer ile diğer yabancı foraminiferlerin bulunmayıșı bu cins ve türlerin yașam koșulları için belirli bir sıcaklık değeri olması gerektiğini ve llıca Burnu kaynaklarındaki değerin çok yüksek olduğunu düșündürür, Bu verilere göre farkı cins ve türler değișik ekolojik koșulların etkisinde kalarak yașamlarını devam ettirebilirler veya yașama imkanını bulamazlar.

Buna karșın geçmiște var olduğu düșünülen ve çok sayıda jips kristali içeren 11 no'lu örnek çevresinde foraminifer çeșitliliğinin oldukça zengin olmasına karșın, ostrakod ve mollusk topluluğu çok fakirdir. Bu duruma termal suyun içermiș olduğu sülfatın neden olduğu düșünülebilir. Yine ortaya çıkan sonuç sülfatın ostrakod ve mollusklar üzerinde olumsuz yönde etken olmasına

\footnotetext{
${ }^{*}$ M. B. Yokeş

e-posta: bakiyokes@gmail.com
} 
karșın foraminiferleri fazla etkilemediğidir. Söz konusu bu yabancı foraminiferlerin Ege Denizi'nde farklı lokalitelerde gerek fiziksel ve gerekse kimyasal özellikleri açısından farkııık sunan ekolojik koșulların etkisinde kalarak belirli alanlarda çoğalıp yayıldıkları, belirli alanlarda ise yașama imkanı bulamadıkları anlașılmıștır.

Bunların dıșında kuzeybatı ve batı Ege Denizi (Yunanistan) kıyı alanlarında yapılan çalıșmalarda cins ve tür çeșitliliği açısından fazla zengin olmayan yabancı bentik foraminiferler gözlenmiștir. Ancak önümüzdeki yıllarda bu alanlarda yapılacak olan ayrıntılı çalıșmalar muhtemelen zengin bir çeșitliliğin varlığını ortaya koyacaktır.

Anahtar Kelimeler: Doğu Ege Denizi kıyıları, termal su kaynakları, yabancı bentik foraminiferler

\section{ABSTRACT}

Benthic foraminifer assemblages have been known to include individuals with colored tests and morphological abnormalities on the coasts of Eastern Aegean Sea (Turkey) and Lesbos Island (Greece). For same reasons, surroundings of the thermal springs that are known to be present or suggested to be present were studied. Great qualitative and quantitative differences were observed in the distributions of the alien species, such as Coscinospira hemprichii, Euthomonacha polita, Peneroplis pertusus, $P$. planatus, Amphisorus hemprichii, Sorites orbiculus, S. variabilis, Cymbaloporetta plana, C. squammosa and Amphistegina lessonii, A. lobifera. The foraminifer assemblages around the thermal spring in Kușadası Bay were found to be rich in alien species, wheras, an exact opposite case was observed in Doğanbey Bay. The assemblages in Karaburun Peninsula and Ilıca Cove also showed differences. The alien foraminifer Amphistegina lobifera, which is typical for the Aegean Sea, was not found in Ilıca, but it was abundant in the recent sediment samples collected from northwest of Karaburun Peninsula. On the north, two thermal springs, with $40^{\circ} \mathrm{C}$ and $51^{\circ} \mathrm{C}$ temperatures, are closely located on the coast of llıca Cape, near Aliaga (Izmir). Except Amphistegina lobifera, the alien species, such as, Peneroplis pertusus, P. planatus Amphisorus hemprichii and Sorites orbiculus, which are typical for Aegean Sea were not observed in the 13 samples collected from the region.

Differences were found when the findings of the present study are compared with previous studies conducted in Kușadası, Doğanbey and northwest of Karaburun Peninsula, which worths attention. Peneroplis pertusus, P. planatus, Coscinospira hemprichii, Sorites orbiculus and Amphistegina lobifera individuals have been observed in the above mentioned localities, but none of them were found in Aliağa samples. These findings can be explained by the differences in environmental factors. For example, except Amphistegina lobifera, the above mentioned benthic foraminifer species have been observed around the thermal spring in Çeșme Ilıca Cove, which had a temperature of $28.4^{\circ} \mathrm{C}$. Southern Pacific and Red Sea originated Euthomonacha polita and Coscinospira acicularis individuals have been abundantly found in Kușadası Bay, Ilıca Cove and northwest of Karaburun Peninsula. The absence of the mentioned five benthic foraminifers and any other alien foraminifer around the two thermal springs with $51^{\circ} \mathrm{C}$ and $40^{\circ} \mathrm{C}$ temperatures on Aliağa llıca Cape, suggests that certain temperatures are required for these genera and species to live and the temperature values of the springs on Ilıca Cape are too high. According to these findings, different genera and species are affected by the environmental conditions and they can, or not, continue to survive.

Besides, numerous gypsum crystals were observed in sample A11 from samples of llıca Cape, suggesting a thermal spring has been present in the past. In contrasts to high biodiversity of the foraminifer fauna, ostracod and mollusc fauna were very poor, which might be the result of sulphate found in the thermal water. Sulphate might have a negative effect on ostracod and molluscs, but not on foraminifers. It is evident that these alien foraminifer species are affected by the physical or chemical environmental conditions, can proliferate and expand in suitable regions, but cannot survive in certain locations.

In addition, alien benthic foraminifers were also observed on the northwestern and western Aegean Sea (Greece), which did not show a diverse genera and species composition. However, detailed studies which should be conducted in the future will probably show the presence of a diverse alien foraminiferal fauna on these coasts.

Keywords: Eastern Aegean Sea coasts, thermal springs, alien benthic foraminifers. 


\section{GiRiș}

Ege Denizi Türkiye kıyı alanlarında gerek karada ve gerekse deniz içinde farklı noktalarda sıcak su çıkıșları vardır. Karada bulunanlar Edremit Körfezi batısından güneye doğru Marmaris Körfezi'ne kadar çok sayıda kaplıcanın varlığına neden olmuștur. Deniz içindekilerden ise en meșhuru Çeșme llıca Koyu kaplıcasıdır. Yine deniz içinde bilinen veya varlığı düșünülen sıcak su çıkıș noktaları güneyden kuzeye doğru șu șekilde sıralanabilir (Șekil 1).

\section{Doğu Ege Denizi-Türkiye kıyıları}

\section{Kușadası Körfezi}

Kușadası Körfezi'nde deniz içi sıcak su çıktısı $19^{\circ} \mathrm{C}$ olarak ölçülmüștür. Çevresinde 4 farklı yönde alınmıș 60 örnekte yapılan çalıșmada; İidia diaphana, Haddonia sp., Nodopthalmidium antillarum, Hauerina diversa, Triloculina affinis, Euthomonacha polita, Peneroplis pertusus, P. planatus, Pyramidulina catesbyi, Brizalina simpsoni, Cyclocibicides vermiculatus, Cymbaloporetta plana, Amphistegina lessonii, $A$. lobifera gibi yabancı foraminiferler bulunmuștur. $\mathrm{Bu}$ noktada dominant cins ve türler Peneroplis pertusus, $P$. planatus ve Amphistegina lobifera'dır. Kaynak çevresinden derlenen 60 örnekten yalnızca ikisi Amphistegina lobifera içermez. Bazılarında ise sayıca 10'dan küçük değerdedir. Çoğunlukla bu değer 100'ün üzerinde olup, dördünde 500'ün üzerinde ve birinde ise 1954'dür. Derinlikler 9.2 - $11.3 \mathrm{~m}$ arasında değișir. Sıcaklık ise $17.5^{\circ} \mathrm{C}$ olarak belirlenmiștir. Yine Kızıldeniz ve Akdeniz'de varlığı bilinmeyen Euthymonacha polita ilk kez Kușadası örneklerinde gözlenmiș (Meriç vd., 2010) ve llıca-Çeșme ile Karaburun Yarımadası KB kıyılarına kadar (İzmir) yayılım göstermiștir. Bu veriler dıșında Kușadası örneklerinde gözlenen renkli kavkılı ve morfolojik bozukluklar sunan bireylerin çokluğu dikkat çekicidir (Yokeș vd., 2014).

\section{Doğanbey Burnu}

Doğanbey Burnu ve çevresinde ise deniz içi küçük mağaralardan çıkan sıcak su dıșında denizde de bazı noktalarda bu gibi çıktılar gözlenmiștir. Örneklerin alınmıș olduğu su derinliği 0.20-31.80 m, dip su sıcaklığı $19.95-23.32^{\circ} \mathrm{C}$ ve dip tuzluluğu \% 38.99 39.24 arasında değișmektedir. Yașam sığ alanlarda oldukça fakir olmasına karșın derin bölgelerde zengindir. Yabancı foraminifer olarak bunlar Iridia diaphana, Peneroplis pertusus, P. planatus, Cyclorbiculina compressa, Sorites orbiculus, Cyclocibicides vermiculatus, Amphistegina lessonii, A. lobifera olarak gösterilebilir.

Çalıșma bölgesinde dikkati çeken en önemli özellik belli noktalardan alınmıș olan örneklerde Amphistegina lobifera bireylerinin bolluğudur. Tuzla Fayı'na bağlı olarak gerek kıyı alanı ve gerekse deniz içinde fay hattına/hatlarında meydana gelen sıcak su çıktılarının varlığı bunun bașlıca nedeni olarak düșünülebilir. Bölge bu özelliği ve foraminifer topluluğu ile Kușadası Koyu'nda bulunan kaynak çevresi topluluğuna büyük benzerlik sunar. Bu değer Kușadası Koyu'ndaki kaynakta $19.6^{\circ} \mathrm{C}$ olup, çevresinde $17.5^{\circ} \mathrm{C}$ 'dir. Doğanbey Burnu'ndan alınan örnek noktalarında ise dip suyu sıcaklığı kaynakta $23.3^{\circ} \mathrm{C}$ olup, çevresinde $19.0^{\circ} \mathrm{C}$ 'dir.

Bölge için diğer bir önemli özellik bol miktarda hem renkli ve hem de morfolojik bozukluk gösteren kavkılara sahip Peneroplis planatus'lara oldukça fazla sayıda rastlanılmasıdır. Yukarıda adı geçen bölgelerde olduğu gibi bu özelliğin kazanılmasında sıcak suların içermiș olduğu ağır metal ve eser elementlerin etkinliği düșünülür. Yine morfolojik bozukluk sunan bazı foraminifer bireyleri de bu düșüncenin bir diğer kanıtı olarak belirtilebilir (Meriç vd., 2018a).

\section{Çeșme llıca Koyu}

Çeșme llıca Koyu'nda aynı șekilde bir termal kaynak varsa da, bu alandan alınan 38 örnek üzerinde yapılan araștırmada Amphistegina lobifera bireyine/ bireylerine rastlanılmamıștır (Meriç vd., 2012a). Buradaki kaynak sıcaklığı $28.4^{\circ} \mathrm{C}$ olarak ölçülmüștür. 1940 'lı yıllarda ise ölçülen değer $59^{\circ} \mathrm{C}$ 'dir (Çağlar, 1946; Bașkan ve Canik, 1983). Zaman içinde kaynak suyunda sıcaklığın azaldığının gerçekleștiği ortaya çıkmaktadır. Bu değer Kușadası Koyu'ndaki kaynakta $19.6^{\circ} \mathrm{C}$ olup, çevresinde $17.5^{\circ} \mathrm{C}$ 'dir. Doğanbey Burnu'ndan alınan örnek noktalarında ise dip suyu sıcaklı̆ı̆ kaynakta $23.3^{\circ} \mathrm{C}$ olup, çevresinde $19.0^{\circ} \mathrm{C}$ 'dir. llıca Koyu'nda (Çeșme-İzmir) varlığı bilinen kaynak çevresinde yapılan çalıșmada 38 güncel çökel örneklerinde yabancı foraminiferlerden Nodopthalmidium antillarum, Spiroloculina antillarum, Triloculina fichteliana, Euthymonacha polita, Coscinospira acicularis, C. hemprichii, Peneroplis arietinus, P. pertusus, $P$. 


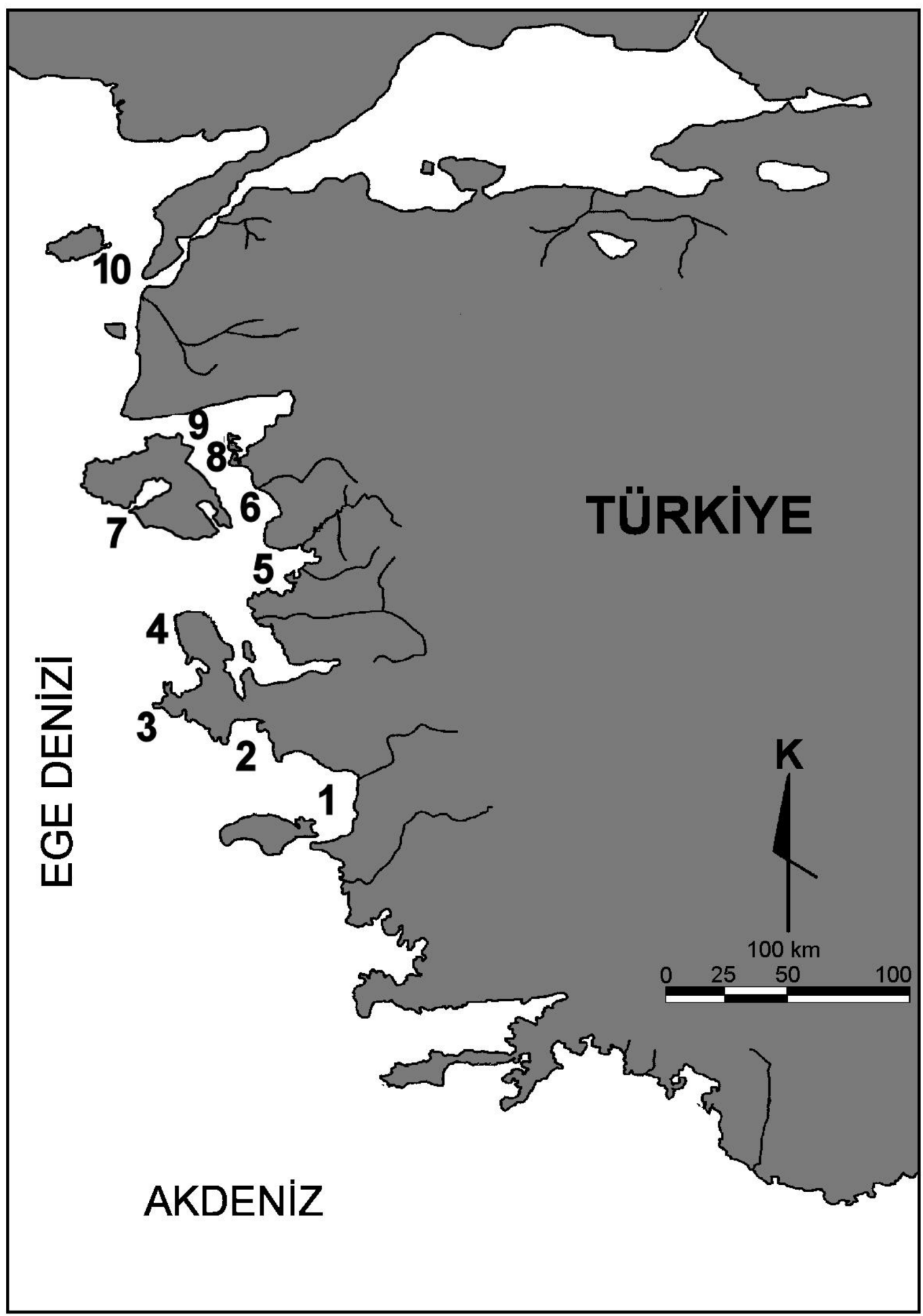

Șekil 1. Doğu Ege Denizi-Türkiye kıyılarındaki termal su çıkıș yerleri: 1. Kușadası Körfezi, 2. Doğanbey Burnu, 3. Çeșme-llıca Koyu, 4. Karaburun Yarımadası, 5. Aliağa-llıca Burnu, 6. Dikili Körfezi, 7. Midilli Adası, 8. Alibey ve Maden adaları, 9. Edremit Körfezi, 10.Gökçeada.

Figure 1. Locations of the thermal spring water spots in the Eastern Aegean Sea-Turkey coasts: 1. Gulf of Kușadası, 2. Doğanbey Cape, 3. Çeșme-llıca Cove, 4. Karaburun Peninsula, 5. Aliağa-llıca Cape, 6. Dikili Bay, 7. Lesbos Island, 8. Alibey and Maden Islands, 9. Gulf of Edremit, 10.Gökçeada. 
planatus, Amphisorus hemprichii, Sorites orbiculus, Polymorphina fistulosa, Cyclocibicides vermiculatus, Cymbaloporetta plana, C. squammosa gözlenmiștir. Bu alanda Amphistegina lobifera'nın bulunmayıșı çaıș̦lan diğer bölgelere göre farklı ekolojik koșulların varlığını ișaret etmektedir. Keza kaynak suyunda radyoaktivite değeri oldukça yüksektir (Meriç vd., 2012a; Meriç vd., 2012b). llıca Koyu'nda Euthymonacha polita dıșında Doğu Ege Denizi'nde ilk kez gözlenen Coscinospira acicularis'in varlı̆ı̆ bu alan için dikkat çekici bir diğer özelliktir. Bu cins ve tür llıca Koyu dıșında Doğu Akdeniz'de yalnızca Hayfa koyunda gözlenmiștir (Yokeș vd., yayınlanmamıș çalıșma).

\section{KB Karaburun Yarımadası}

Karaburun Yarımadası kuzeybatı kesiminde Amphistegina lobifera'ya bol olarak rastlanılması ilginç bir durumu ortaya koyar (Meriç vd., 2012b). Bu alanda herhangi bir sıcak su kaynağının varlığı henüz tespit edilememiștir. Fakat sıcak su kaynağını kanıtlayacak renkli kavkılı ve morfolojik bozukluk gösteren kavkılara sahip bentik foraminiferlerin bolluğu bu düșünceye destek verir.

Karaburun Yarımadası GB'sında Tuzla Koyu'ndan derlenmiș olan 45 ve KD'sunda Karaburun yerleșim alanı GD'dan alınan 45 güncel çökel örneğinde yabancı foraminiferlerden Iridia diaphana, Nodopthalmidium antillarum, Triloculina fichteliana, Articulina carinata, Euthymonacha polita, Peneroplis arietinus, $P$. pertusus, P. planatus, Sorites orbiculus, S. variabilis, Cymbaloporetta plana, C. squammosa, Amphistegina lobifera gibi cins ve türler gözlenmiștir. Özellikle Tuzla Koyu'nda Amphistegina lobifera bireylerinin çok sayıda rastlandığı noktalarda su sıcaklığı 16.8-17.0 $0^{\circ} \mathrm{C}$ değerdedir. Yine bu alanda oldukça fazla sayıda ve gelișmiș Euthymonacha polita bireylerinin varlığı, söz konusu foraminiferin Kușadası sıcak su kaynağından itibaren kuzeye doğru göç ettiğini ve ekolojik özelliklerin uygunluğu nedeniyle bu alanlarda çoğaldığını ortaya koymaktadır (Meriç vd., 2010; Meriç vd., 2012c).

\section{Aliağa llıca Burnu}

Çandarlı Körfezi'nin güney ucunda batıda llıca Burnu ile doğuda Kızıl Burun arasında kalan alanda deniz kıyısında bulunan biri deniz seviyesinde $51^{\circ} \mathrm{C}$, diğeri $70-80 \mathrm{~cm}$ yukarıda bulunan ve su sıcaklığı $40^{\circ} \mathrm{C}$ olan iki küçük mağara içinden çıkan sıcak su çıkıșlarının çevresinde yașayan bentik foraminiferler üzerindeki etkisini belirlemek amacıyla bir araștırma yapılmıștır. Bu iki kaynak dıșında 11 no'lu örnekte gözlenen çok sayıdaki tekçe jips kristallerinin varlığı bu alanda yakın geçmiște faya bağlı üçüncü bir sıcak su kaynağının var olduğunu ortaya koymaktadır.

Bu alandan alınan 13 genç çökel örneğinde Ege Denizi'nde sıkça rastlanılan Coscinospira hemphrichii, Peneroplis pertusus, P. planatus, Amphisorus hemprichii, Sorites orbiculus, S. variabilis ve Amphistegina lobifera gibi yabancı foraminifer bulunmamıștır. Bunun dıșında incelenen örneklerde Ege Denizi'nin farklı noktalarında gözlenen yabancılardan hiç biri bu alanda mevcut değildir. Bu durum yukarıda belirtilen sıcak su çıkıșları çevresi ile bölge için çok farklı bir özellik sunmaktadır. Burada etken olanlar su sıcaklığının $51^{\circ} \mathrm{C}$ ve $40^{\circ} \mathrm{C}$ derece olması ve/veya suyun kimyasal özeliklileri ile yüksek radyoaktivite olabilir. Yine de renkli ve morfolojik bozukluk gösteren birey sayısı oldukça azdır (Meriç vd., 2018b, yayın așamasında).

\section{Dikili Körfezi}

Dikili Körfezi kuzeyi ve güneydoğusundan alınmıș olan iki örnekte yabancı foraminiferlerden Peneroplis pertusus ile $P$. planatus bireyleri bulunmuștur. Bunlardan birinde rastlanılan Peneroplis planatus bireyi bilinen ağız șekli ve konumları açısından çok farklı olarak anormal bir durumu sergilemektedir (Meriç vd., 2003). Yine karada yakın alanda bir kaplıcanın varlığı bu noktada da deniz içi sıcak su çıktısının/çıktılarının var olabileceğini düșündürmektedir.

\section{Alibey ve Maden adaları çevresi}

Alibey ve Maden adaları çevresinden derlenen 4 karottan alınmıș olan 96 örneğe ait foraminifer topluluğu yine Kușadası, Doğanbey ve Karaburun Yarımadası Tuzla Koyu foraminifer topluluklarına benzerlik sunar. Örneklerde Iridia diaphana, Spiroloculina antillarum, Coscinospira hemprichii, Peneroplis pertusus, P. planatus, Sorites orbiculus, Acervulina inhaerens, Amphistegina lobifera gibi yabancı foraminiferler gözlenmiștir. Fark, incelenen 96 örnekten yalnız birinde tek fert olarak Amphistegina lobifera'ya rastlanılmıș olmasıdır. Bunun dıșında kor 4b'de anormal denilebilecek sayıda renkli Peneroplis pertusus ve $P$. planatus bireyleri bulunmuștur. Yine kor 3a'da 
çok sayıda serbest olarak, ayrıca hem foraminiferler ve hem de Posidonia'lar çevresinde çok sayıda jips kristalleri gözlenmiștir (Meriç vd., 2017). Bu durum korun alındığı nokta çevresinde yakın bir sürede sıcak su çıktııının kanıtı olarak belirtilebilir.

\section{Edremit Körfezi}

Edremit Körfezi'nden derlenen 11 örnek üzerinde yapılan çalıșmada Baba Burnu güneydoğusundan alınmıș olan 2 no'lu örnek 30 cins ve 45 tür gibi zengin bir foraminifer topluluğuna sahiptir. Bunlar arasında gözlenen ve bir yabancı foraminifer olarak bilinen Astacolus crepidilus bireylerinin varlığı bu alan için farklı bir diğer özelliktir. Yine 2 no'lu örnekte bulunan zengin bryozoon topluluğunu olușturan Adeonella polystomella Türkiye Akdeniz kıyıları dıșında Fas, Kızıldeniz, Hint Okyanusu ve Pasifik Okyanusu'nda yașamaktadır. Margaretta cereoides yine Akdeniz dıșında Kızıldeniz'de de bulunmuștur. Sıcak denizleri tercih eden bu organizmaların Edremit Körfezi kuzeyini yașam alanı olarak tercih etmeleri, bu alanda tektonizmaya bağı olarak karada kıyı kesimlerinde gözlendiği gibi deniz içinde de faylara bağı termal kaynakların varlığını desteklemektedir (Meriç vd., 2012e).

\section{Gökçeada}

Gökçeada çevresinden derlenmiș olan 34 örneğin çoğunda, özellikle adanın güneydoğu kesiminde daha fazla olarak yabancı foraminiferlerden Peneroplis pertusus, P. planatus, Sorites orbiculus ile Amphistegina lobifera bireylerine rastlanılmıștır. Bunlardan Sorites orbiculus ile Amphisteggina lobifera yalnız Aydıncık Limanı'ndan derlenen 30 no'lu örnekte bulunmuștur. Yine adanın güneydoğu kesiminde bol olarak gözlenen Peneroplis planatus bireylerinin sarı ve turuncu renklerde olması bu kesimde de Midilli Adası benzeri Fe'ce zengin sıcak su çıktılarının varlığını düșündürür (Meriç ve Avșar, 2001).

\section{Batı Ege Denizi Yunanistan kıyıları ve Midilli Adası}

Durumu kuzeybatı Ege Denizi ve batı Ege Denizi kıyı alanlarına yönlendirirsek Yunanistan kıyı alanlarının farklı noktalarında zengin denilebilecek bir yabancı bentik foraminifer topluluklarının varlığı ile karșılașılır.

Farklı araștıııılar tarafından bunlar Triloculina fichteliana, Coscinospira hemprichii, Peneroplis pertusus,
P. planatus, Sorites orbiculus, Cymbaloporetta plana, Planogypsina acervalis, Amphistegina lobifera olarak belirlenmișitir. Adı geçen yabancı foraminiferler içinde en fazla yayılım gösteren Amphistegina lobifera'dır (Triantaphyllou vd., 2009; Koukousioura vd., 2010; Koukousioura vd., 2011; Triantaphyllou vd., 2012; Dimizia vd., 2016).

Midilli Adası güneydoğusunda Mytilene yerleșim alanı kuzeybatısında Pirgi Thermis doğusunda kıyı alanı zengin bir bentik foraminifer topluluğuna sahiptir. Bunlar arasında gözlenen Peneroplis pertusus, $P$. planatus ile Sorites orbiculus bireyleri bu alanadaki sıcak su koșullarının varlığını belirtir. Bunlar arasında çok sayıda Peneroplis pertusus ve $P$. planatus bireylerinin turuncu-sarı renkte olması adı geçen alan için dikkat çekici bir özelliktir. Bu durum bölgedeki Fe içeren yer altı sularının varlığına ișaret eder. Adanın güneydoğusunda su sıcaklığı $39.7^{\circ} \mathrm{C}, 43.5^{\circ} \mathrm{C}, 46.5^{\circ} \mathrm{C}$, $46.9^{\circ} \mathrm{C}, 69^{\circ} \mathrm{C}$ arasında değișen, ve tuzlu su özelliğini tașıyan çok sayıda kaplıca bulunmaktadır. Sonuçta adanın doğusunda, kuzeybatı-güneydoğu doğrultulu büyük bir fayın bulunması (Șengör vd., 1985; Çağatay vd., 1998), buna bağlı olarak deniz içinde de ikincil, hatta üçüncül fayların olabileceği düșüncesi, adı geçen alandaki sıcak su çıktılarının oluștuğunu ve bu alanlarda farklı foraminifer topluluklarını etkilediğini düșündürür (Meriç vd., 2002; Meriç vd., 2014).

\section{EGE DENIZi MEVSIMSEL AKINTI SISTEMLERI}

Ege Denizi'nde yüzey akıntısının hız ve yönleri, mevsimlere bağlı olarak değișmektedir. Yüzey akıntılarını en fazla etkileyen faktörler, meteorolojik koșullar ile Kuzeydoğu Ege Denizi'nde, Çanakkale Boğazı'ndan, Marmara Denizi aracılığı ile gelen Karadeniz suyudur. Meteorolojik faktörlerden en etkilisi rüzgâr hız ve yönü ile buna bağlı dalga yönü, hava sıcaklığı değișimleridir. Ayrıca batimetri-sualtı morfolojisi ile adaların konumu da önemli ve yönlendirici faktörlerdir (Zodiatis vd.,1996; Eryılmaz, 1997,1999; Beșiktepe, 2015).

Illkbahar mevsiminde, Kuzey Ege Denizi'nde ana akıntı sistemleri, Yunanistan anakarası tarafında KB'dan GD'ya, Türkiye tarafında KD'dan GB'ya orta kesimde ise K'den G'ye doğru 0,6-0,8 km/s hızla, Orta Ege Denizi'ne doğru devam etmektedir (Lacombe ve Tchernia, 1972; Miller, 1972; Eryılmaz, 1997; Eryılmaz, 1999; Yücesoy-Eryılmaz ve Eryılmaz, 2002; 
El-Geziry ve Bryden, 2010; Eryılmaz ve Yücesoy-Eryılmaz, 2012a; Eryılmaz ve Yücesoy-Eryılmaz, 2012b; Beșiktepe, 2015). Orta Ege'de Kiklad (Cyclades) Adaları'nın akıntı yolunu daraltması ve anakaraların birbirine daha yakın olması ile deniz alanındaki daralma kuzeyden güneye akan su kütlesini sıkıștırmakta, burada akıntı hızı yaklașık 0.9 km/s'a çıkmaktadır (Eryılmaz, 1997; Eryılmaz, 1999). Güney Ege'ye doğru ilerleyen akıntı yolu üzerine, Kiklad (Cyclades) adalarının çıkması akıntı su kütlelerinin yelpaze gibi açılmasına, GB, G ve GD ya doğru yönlenmesine neden olmaktadır. Bu bölgede akıntı hızı, 0.9 km/s'dan 0.60.8 km/s'a düșmektedir (Șekil 2B). Yelpaze șeklinde yayılmıș olarak gelen akıntı, önüne Girit Adası'nın çıkması ile engellenmekte, akıntının bir kolu Girit Adası ile Peloponez Yarımadası arasından, $0.9 \mathrm{~km} / \mathrm{s}$ hız ile batıya doğru devam ederken, diğer kol ise (0.8-0.9 km/s) Girit Adası doğusundan, Doğu Akdeniz'e yönelmektedir (Eryılmaz, 1997; Eryılmaz, 1999; Poulos vd., 1997; Papadopoulos vd., 2009; Zeri vd., 2014; Politikos vd., 2017) (Șekil 2A, 2B).

Yaz mevsiminde, K Ege Denizi'nde ana akıntı sistemleri, Türkiye tarafında saat yönünün tersine yay çizerek KD'dan GD'ya doğru 1.1 km/s hızla, Orta Ege Denizi'ne devam etmektedir. Orta Ege'de Kiklad (Cyclades) Adaları'nın doğusundan kuzeyden güneye doğru, yaklașık 0.9 km/s hızla ilerlemekte (Eryılmaz, 1997; Eryılmaz, 1999; Beșiktepe, 2015), Güney Ege'de Kiklad (Cyclades) Adaları ile Oniki Adalar'ın (Dodecanese Islands) akıntıyı, Girit Adası'nın kuzeyinde iki kola ayırarak, ana kolun GB'ya $(0.9 \mathrm{~km} / \mathrm{s})$, diğer kolun ise GD yönüne (0.7-0.8 km/s) doğru devam etmesine neden olmaktadır (Șekil 2A, 2C). Girit Adası ile Peloponez Yarımadası arasından, 0.9 km/s hız ile batıya doğru devam eden ana kolun bir kısmı, Girit'in güneyinde doğuya doğru yönelerek (0.9 km/s), Girit Adası doğusundan gelen ve batıya doğru ilerleyen akıntı ile karșılașıp yönünü GD'ya çevirmektedir (Eryılmaz, 1997; Eryılmaz, 1999; Poulos vd., 1997; Papadopoulos vd., 2009; Zeri vd., 2014; Politikos vd., 2017) (Șekil 2A, 2C).

Sonbahar mevsiminde, Ege Denizi'nde akıntı sistemleri diğer mevsimlere göre farklılık gösterir. İlkbahar, yaz ve kıș mevsimlerinde, genellikle kuzeyli yönlerden güneye doğru olan akıntı, bu mevsimde güneyden kuzeye doğru yön değiștirir. Kuzey Ege Denizi'nde, boğaz akıntısı ve rüzgar nedeni ile kuzeyden güneye ve Çanakkale Boğazı'ndan batıya doğru akıntı görülmektedir (Eryılmaz, 1997; Eryılmaz, 1999; Yücesoy-Eryılmaz ve Eryılmaz, 2002; El-Geziry ve Bryden, 2010; Yücesoy Eryılmaz vd., 2005; Beșiktepe, 2015). Bu akıntıların hızı 0.5-0.7 km/s arasında değișir, zaman zaman güneyli rüzgarların etkisi ile çok zayıflar, yer yer durma noktasına gelebilir. Güneydoğu Akdeniz'den Kaș-Fethiye-Rodos istikametinden gelen ve batıya doğru 1.1-1.2 km/s hızla ilerleyen akıntı Rodos Adası'nı geçtikten sonra KB'ya yönelerek, Orta Ege Denizi'ne doğru devam eder. Bu bölgede, Kiklad (Cyclades) Adaları'nın doğu kesiminde yer alan adalar ile Oniki Adalar (Dodecanese Islands) bu akıntının önünü keserek, akıntıyı değișik kollara ayırır ve akıntının hızını düșürür (0.7-0.9km/s) (Eryılmaz, 1997; Eryılmaz, 1999; Eryılmaz ve Yücesoy Eryılmaz, 2008). Bu akıntı Anadolu kıyılarındaki yerel akıntıların da yönünü değiștirerek Orta Ege Denizi'nin kuzeyinde kuzeyden gelen akıntı ve rüzgârların etkisi ile, Anadolu kıyılarından Yunanistan'a doğru saat yönünün tersine bir istikametle döner (Eryılmaz, 1997; Eryılmaz,1999; Eryılmaz ve Yücesoy-Eryılmaz, 2016), Güney Sporad Adaları'nın alt ucundan geriye doğru, kuzeyden güneye ilerleyen, Yunanistan kıyılarına yakın ve Kiklad (Cyclades) Adaları arasından geçen bir akıntı kolu olușturur (El-Geziry ve Bryden, 2010; Eryılmaz ve Yücesoy Eryılmaz, 2014). Girit Adası ile Peloponez Yarımadası arasından, 0.8-0.9 km/s hız ile batıya doğru devam eder. Girit'in batısında doğuya yönelerek $(0.9 \mathrm{~km} / \mathrm{s})$ adanın güneyinde, doğuya ilerleyen bir akıntı olușturur (Eryılmaz, 1997; Eryılmaz, 1999) (Șekil 2A, 2D).

Kıș mevsiminde ise, kuzeyli rüzgarların etkisi ile tüm Ege Denizi'nde kuzeyden güneye doğru akıntılar olușmakta ve bu akıntıların hızı 0.9-1.2 km/s arasında değișmekte, artan rüzgar hızına bağlı olarak yer yer ve dönem dönem artıș göstermektedir (Lacombe ve Tchernia, 1972; Miller, 1972; Poulos vd.,1997; Papadopoulos vd., 2009; Eryılmaz ve Yücesoy Eryılmaz, 2012a; Eryılmaz ve Yücesoy Eryılmaz, 2012b; Zeri vd., 2014; Beșiktepe, 2015; Politikos vd., 2017). Orta Ege ile güney Ege Denizi sınırında, Kiklad (Cyclades) Adaları'nın engellemesi ile iki kola ayrılarak GB (1.3$1.4 \mathrm{~km} / \mathrm{s}$ ) ve GD yönlerine ilerleyen (0.7-0.8 km/s) akıntıları olușmaktadır (Eryılmaz, 1997; Eryılmaz, 1999; El-Geziry ve Bryden, 2010; Eryılmaz ve Yücesoy-Eryılmaz, 2016). 0.9 km/s hız ile devam eden batı kolu, Girit Adası ile Peloponez Yarımadası arasından geçerek Girit'in güneyinde doğuya doğru yönelmektedir. Doğu kolu ise Girit Adası batısından gelen ve 

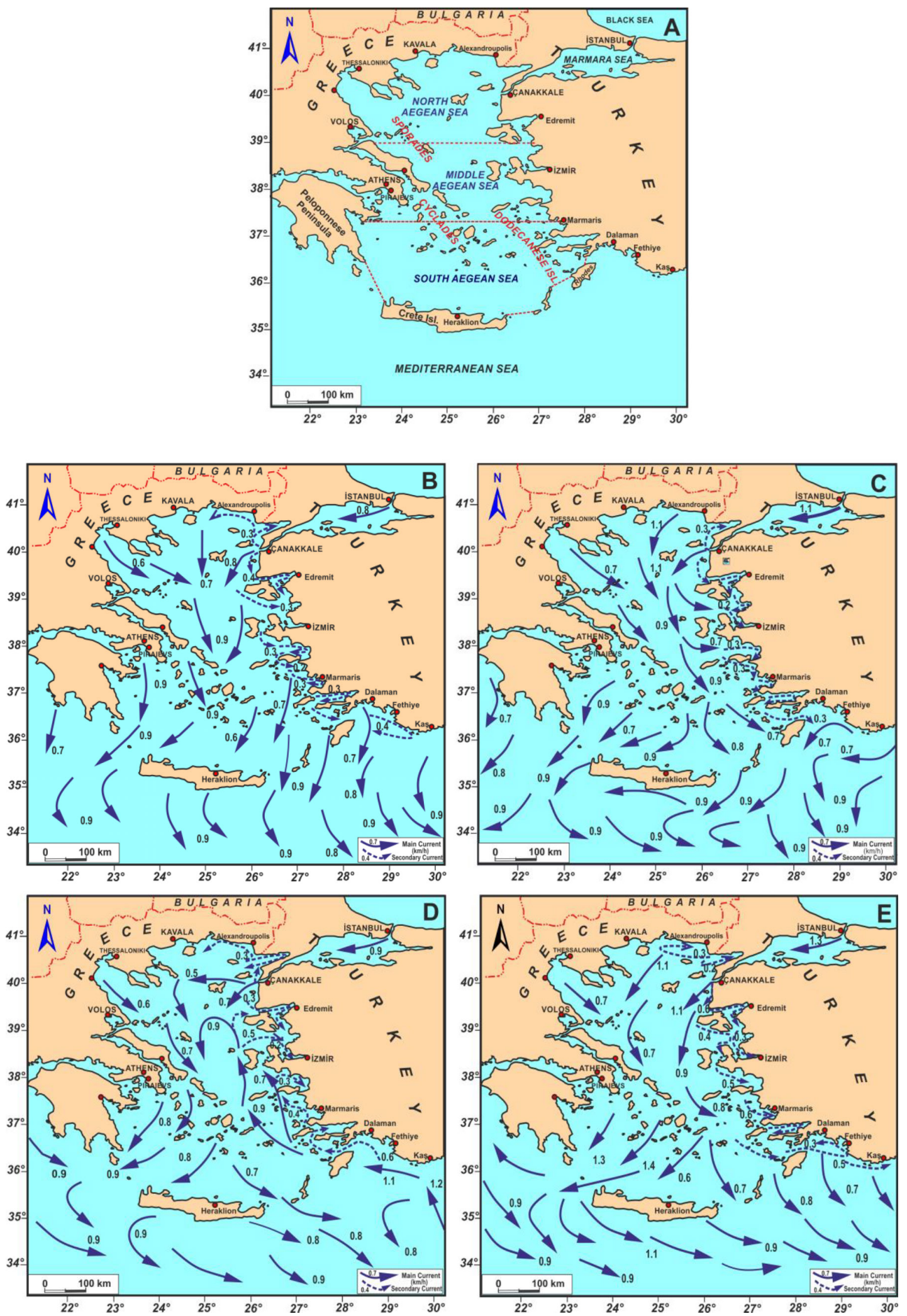

Șekil 2. Ege Denizi mevsimsel akıntıları. A-Yer bulduru haritası, B- İlkbahar mevsimi, C-Yaz mevsimi, D-Sonbahar mevsimi, E-Kıș Mevsimi (Eryılmaz, 1997; Eryılmaz, 1999).

Figure 2. Seasonal currents in the Aegean Sea. A-Map of the study area, B-Spring, C-Summer, D-Autumn, E-Winter (Eryılmaz, 1997, 1999). 
doğuya doğru ilerleyen akıntı ile birleșerek yönünü GB'ya çevirmektedir (Șekil 2A, 2E).

\section{SONUÇLAR}

Kușadası Körfezi'nde deniz içi sıcak su çıktısı $19^{\circ} \mathrm{C}$ sıcaklıkta olup kaynak çevresinde $17.5^{\circ} \mathrm{C}$ olarak belirlenmiștir. Doğanbey Burnu ölçülen sıcaklık değerleri kaynakta $23.3^{\circ} \mathrm{C}$, çevresinde $19.0^{\circ} \mathrm{C}$ 'dir. Doğanbey Burnu örnekleri özelinde, Amphistegina lobifera Larsen bireyleri 0-16 m derinlikler arasında, yaklașık $20-23^{\circ} \mathrm{C}\left(20.0-23.3^{\circ} \mathrm{C}\right)$ sıcaklık aralığında çok az miktarda (3-4 birey kadar) görülmektedir. 18-32 m derinlikleri arasında yaklașık $19-20^{\circ} \mathrm{C}\left(19.0-20.3^{\circ} \mathrm{C}\right)$ sıcaklıkta bol miktarda (25 bireyden fazla) bulunmaktadır. Bu duruma göre, bölge için Amphistegina lobifera'nın ideal yașam aralığı 18-32 metre derinlik ve yaklașık $19-20^{\circ} \mathrm{C}$ sıcaklık olarak belirlenmiștir.

Doğanbey Burnu çevresi için sıcaklık değerleri dikkate alındığında Amphistegina lobifera'nın fazla sıcak ortamları tercih etmediği ortaya çıkmaktadır. Bazı araștırıcılar (Zmiri vd., 1974; Langer and Hottinger, 2000; Langer vd., 20012) amphisteginid foraminiferlerin Doğu Akdeniz'de yayılmasında deniz suyu sıcaklık değerlerindeki değișimin bașlıca etken olduğunu ileri sürmektedirler. Fakat araștırıcılar sıcaklık ile ilgili olarak sınırlı bir değer ortaya koymamıșlardır. llıca Koyu sıcak su çıktısı çevresinde Amphistegina bireylerine rastlanılmamasının nedeni olarak su SIcaklığının elde edilen değerlere göre yüksek değerli olması dıșında, bu alanda radyoaktivitenin yüksek olması da gösterilebilir (Meriç vd., 2012a). Ayrıca Doğanbey Burnu örnekleri foraminifer, ostrakod ve mollusk topluluğu açısından değerlendirildiğinde 7, 8, 9, 10 ve 11 no'lu örneklerin zengin bir topluluğa sahip olması, çalıșma alanı için ortak bir özelliğin varlığını ortaya koymaktadır (Meriç vd., 2018a).

llıca Koyu Amphistegina lobifera'nın yokluğuna karșın gerek yabancı ve gerekse renkli ve morfolojik bozukluk sunan kavkılara sahip foraminifer bireyleri açısından çok zengindir. Karaburun Yarımadası Tuzla Koyu'nda gözlenen foraminifer topluluğu llıca Koyu'ndan farklı olarak Amphistegina lobifera Larsen dahil olmak üzere benzer topluluğa sahiptir.

Aliağa llıca Burnu'ndaki sıcaksu çıktıları çevresinde Coscinospira hemphrichii, Peneroplis pertusus, $P$. planatus, Amphisorus hemprichii, Sorites orbiculus, S. variabilis ve Amphistegina lobifera gibi yabancı foraminiferlere rastlanılmamıștır. İki kaynaktaki su Sıcaklığının $51^{\circ} \mathrm{C}$ ve $40^{\circ} \mathrm{C}$ olmasının bu konuda bașlıca etken olduğu/olabileceği düșünülür. Ayrıca kaynak sularının radyoaktivitesinin de bu konuda etken olabileceği dikkate alınmalıdır.

Dikili Körfezi'nde morfolojik bozukluk sunan bir Peneroplis planatus bireyi bu alanda deniz içinde varlığı düșünülen sıcak su çıktısı/çıktıları nedeniyle olușmuștur. Yakın alanda Midilli Adası güneydoğu kesiminde var olan renkli Peneroplis pertusus ve $P$. planatus bireylerinin varlığı bu alandaki benzer özelliklerin sonucudur.

Alibey ve Maden adaları çevresinden derlenen örneklerden yalnız birinde çok az sayıda Amphistegina lobifera Larsen bulunmasına karșın diğer yabancı foraminiferlerin varlığı düșündürücüdür. 3a korundaki belirli seviyelerde așırı bollukta jips kristallerinin bulunușu bu alanda belli bir dönemde oldukça sıcak su çıktısı nedeniyle sıcaklık değerinin yükseldiğini ortaya koymaktadır. Keza Aliağa llıca Burnu'nda 11 no'lu örnekte gözlenen jips kristalleri de benzer özelliği belirtmektedir.

Edremit Körfezi kuzey kesiminde gözlenen Astacolus crepidulus ile Kızıldeniz, Hint Okyanusu, Pasifik Okyanusu'nda yașamını sürdüren bryozoonların varIığı yine körfezin belirli noktalarındaki sıcak su çıktısı/ çıktıları nedeniyle açıklanabilir.

Gökçe Ada çevesindeki çoğu noktalarda saptanan renkli Peneroplis pertusus, $P$. planatus bireyleri dișında, Sorites orbiculus ve Amphistegina lobifera'nın varlığı bu bentik foraminiferlerin deniz suyunun farklı sıcaklık değeri/değerleri ve içerdiği ağır metal ile eser elementler nedeniyle bu alanda/alanlarda yașamlarını sürdürdüğünü ortaya koymaktadır.

Kuzeybatı ve batı Ege Denizi Yunanistan kıyı alanlarında fazla olmayan cins ve türler ile temsil edilen yabancı foraminiferler oldukça geniș bir yayılım sunarlar. İleride bu alanlarda yapılacak olan ayrıntılı çaıșmalar daha zengin bir topluluğun varlığını ortaya koyabilecektir.

Sonuç olarak Pasifik Okyanusu, Hint Okyanusu, Kızıl Deniz ve az sayıda da olsa Atlas Okyanusu kökenli foraminiferlerin bölgeye gelen gemilerin balast suları ile Ege Denizi'nin farkla noktalarına tașındığı, ortama uyum sağlayanların çoğalıp yayıldığı, bu konuda en büyük etkenin akıntı sistemi olduğu anlașılmaktadır. Bunun dıșında belli foraminifer cins ve türleri için 
ekolojik koșullardan sıcaklık değeri sınırlarının farklı olduğu ortaya çıkmaktadır. Yine sıcak suların içerdiği ağır metal ve eser elementlerin de bu konuda bașlıca etkenlerden biri olduğu gerçektir. Aliağa çalıșmasında güncel çökellerde B ve Li değerleri yüksek olup, kaynak sularında Sr yüksektir. Ayrıca suların radyoaktif özelliklerinin de bu durum ile ilgili olabileceği söz konusudur. Çünkü denizden ve mağara içinden alınmıș olan sularda toplam alfa ve toplam beta (Bq/l) değerleri referans değerden yüksek ölçülmekle birlikte denizden alınmıș olan örnekte toplam alfa ve beta daha yüksektir. Toplam çözülmüș madde miktarı (TDS) (g/l) ise mağara içindeki kaynak suyunda yüksektir (Meriç vd., 2018b).

Bu gibi özelliklerin veya herhangi birinin foraminifer yașamında etken olduğu/olabileceği düșünülür. Yine adı geçen alanlarda bulunmuș olan farklı cins ve türlere ait birlikteliklerin varlığı Ege Denizi için bir diğer önemli özelliktir. Peneroplis planatus-Coscinospira hemprichii, Peneroplis pertusus-Coscinospira hempricihii (Meriç vd., 2008), Vertebralina striata- Coscinospira hemprichii (Meriç vd., 2009), Peneroplis pertusus-Peneroplis planatus (Meriç vd., 2012d) gibi doğa harikası birliktelikler bunun en güzel örnekleridir.

\section{KAYNAKLAR}

Bașkan, E., Canik, B., 1983, Türkiye sıcak ve mineralli sular haritası, Ege bölgesi. MTA Enstitüsü yayınları, 189, 80 s., Ankara.

Beșiktepe, Ș. T., 2015. Physical Oceanography of the Aegean Sea: A Review the Aegean Seamarine Biodiversity, Fisheries, Conservation and Governance, Edited By: T. Katağan, A. Tokaç, Ș. Beșiktepe, B. Öztürk, Turkish Marine Research Foundation (TUDAV), Publication No: 41. 27-39. Istanbul, Turkey.

Çağatay, M. N., Görür, N., Alpar, B., Saatçılar, R., Akkök, R., Sakınç, M., Yüce, H., Yaltırak, C., Kușçu, I., 1998, Geological evolution of the Gulf of Saros, NE Aegean Sea. Geo-Marine Letters, 18, 1-9.

Çağlar, K. Ö., 1946, Türkiye maden suları ve kaplıcaları. Maden Tetkik ve Arama Enstitüsü yayınları, B, 11, 791 s., Ankara.

Dimiza, M. D., Triantaphyllou, M. V., Koukousioura, O., Hallock, P., Simboura, N., Karageorgis, P., Papathanasiou, E., 2016, The foram stress index: A new tool for environmental assassment of soft-bottom environments using benthic foraminifera. A case study from the Saronikos Gulf, Greece, Easetrn Mediterranean. Ecological Indicators, 60,611-621.

El-Geziry, T.M. and Bryden, G., 2010. The Circulation Pattern in the Mediterranean Sea: Issues For Modeller Consideration. Journal of Operational Oceanography, 3:2, 39-46, DOI: 10.1080/1755876X.2010.11020116, ISSN: 1755-876X, 1755-8778.

Eryılmaz M., 1997. Ege Denizi Güncel Çökel Dağılımına Etkileyen Oșinografik Faktörler. Yayımlanmamıș Rapor, 51 s., Dz.K.K., SHOD, İstanbul.

Eryılmaz M., 1999. Ege Denizi Akıntı Sistemleri, Yayımlanmamıș Rapor, 29 s., Dz.K.K., SHOD, İstanbul.

Eryılmaz, M. and Yücesoy- Eryılmaz, F., 2008; Oceanography And Submarine Sediment Distribution in Marmaris-Kaș Region of Southwest Turkey. Micropaleontology, Vol. 54, Nos, 3-4, 187-197.

Eryılmaz, M. ve Yücesoy Eryılmaz, F., 2012a. Edremit Körfezi'nin Oșinografisi. SBT 2012, Sualtı Bilim Ve Teknolojileri Toplantıları, 17-18 Kasım 2012 Bildiriler Kitabı, 117-126, İstanbul.

Eryılmaz, M. ve Yücesoy Eryılmaz, F., 2012b. Dikili Kanalı'nın (KD Ege Denizi) Oșinografisi. SBT 2012, Sualtı Bilim Ve Teknolojileri Toplantıları 17-18 Kasım 2012 Bildiriler Kitabı, 127135, İstanbul.

Eryılmaz, M. and Yücesoy Eryılmaz, F., 2014. Underwater Morphology, Oceanography and Recent Sediment Distribution of Kușadașı Bay (West of Turkey). Fifth International Symposium "Monitoring Of Mediterranean Coastal Areas: Problems And Measurement Techniques" Livorno (Italy) (17-18-19 June 2014), Proceeding Book, 655-664, ISBN:978-8895597-19-5, CNR-IBIMET Firenze, Italy.

Eryılmaz, M. and Yücesoy Eryılmaz, F., 2016. Recent Sediment Distribution and Oceanography of Ildır Bay (Karaburun Peninsula-Aegean Sea). Sixth International Symposium. Monitoring Of Mediterranean Coastal Areas: Problems And Measurement Techniques (September 28-29, 2016), Proceeding Book, 193-202, 
Firenze University Press, 2017. ISBN 97888-6453-427-5 (Print), ISBN 978-88-6453428-2 (Online) Livorno, Italy.

Koukousioura, O., Dimiza, M. D., Triantaphyllou, M. V., 2010, Alien foraminifers from Greek coastal areas (Aegean Sea, Eastern Mediterranean). Mediterranean Marine Science, 11 (1), 155-172.

Koukousioura, O., Dimiza, M. D., Triantaphyllou, M. V., Hallock, P., 2011, Living benthic foraminifera as an environmental proxy in coastal ecosystems: A case study from the Aegean Sea (Greece, NE Mediterranean). Journal of Marine Systems, 88, 489-501.

Langer, R. M., Weinmann, A. E., Lötters, S., Rödder, D., 2012, "Strangers" in paradise modeling the biogeographic range expansion of the foraminifera Amphistegina in the Mediterranean Sea. Journal of Foraminiferal Research, 42 (3), 234-244.

Langer, R. M. and Hottinger, I., 2000, Biogeography of selected "larger" foraminifera. Micropaleontology, 46, supplement 1, 105-126.

Lacombe, H. and Tchernia, P., 1972. Caractères Hydrauliques et Circulation des Eaux en Mediterranée. The Mediterranean Sea: A Natural Sedimentation Laboratory (ed. D.J. Stanley), Dowden Hutchinson \& Ross, Inc., p.25-36. ISBN: 0-87933-010-4, Stroudsburg.

Meriç, E. and Avșar, N., 2001, Benthic foraminiferal fauna of Gökçeada Island (Northern Aegean Sea) and its local variations. Acta Adriatica, 42 (1), 125-150.

Meriç, E., Avșar, N., Bergin, F., 2002, Midilli Adası (Yunanistan-Kuzeydoğu Ege Denizi) bentik foraminifer faunası ve bu toplulukta gözlenen yerel değișimler. Ç. Ü. Yerbilimleri (Geosound), 40-41, 177-193, Adana.

Meriç, E., Avșar, N., Bergin, F., Barut, İ., 2003, Dikili Körfezi'nde (Kuzeydoğu Ege Denizi-Türkiye) bulunan üç anormal bentik foraminifer örneği: Peneroplis planatus (Fichtel ve Moll), Rosalina sp. ve Elphidium crispum (Linne) hakkında. M.T.A. Dergisi, 127, 67-81, Ankara.

Meriç, E., Yokeș, M. B., Nielsen, J. K., Görmüș, M., Avșar, N., Dinçer, F., 2008, Abnormal formations in peneroplid foraminifers: Peneroplis-
Coscinospira togetherness. Anales de Biologia, 30, 1-7.

Meriç, E., Yokeș, M. B., Avșar, N., Bircan, C., 2009, A new observation of abnormal development in benthic foraminifers: Vertebralina-Coscinospira togetherness. Marine Biodiversity Records, 2, e167, 1-6.

Meriç, E., Yokeș, M.B., Avșar, N., Bircan, C., 2010, An oasis for alien benthic foraminifera in the Aegean Sea. Aquatic Invasions, 5 (2), 191 195.

Meriç, E., Avșar, N., Nazik, A., Yokeș, M., Barut, I. F., Eryılmaz, M., Kam, E., Tașkın, H., Bașsarı, A., Dinçer, F., Bircan, C., Kaygun, A., 2012a, Ilıca Koyu (Çeșme-İzmir) bentik foraminiferostrakod toplulukları ile Pasifik Okyanusu ve Kızıldeniz kökenli göçmen foraminiferler ve anormal bireyler. M.T.A. Dergisi, 145, 62-78, Ankara.

Meriç, E., Yokeș, B., Avșar, N., Kırcı-Elmas, E., Dinçer, F., 2012b, A new record in eastern Aegean Sea (Turkey): Polymorphina fistulosa. Marine Biodiversity Records, Journal of Marine Biological Association of the United Kingdom, 5, e103, 1-3.

Meriç, E., Avșar, N., Nazik, A., Yokeș, Dora, Ö., Barut, I. F., Eryılmaz, M., Dinçer, F., Kam, E., Aksu, A., Tașkın, H., Bașsarı, A., Bircan, C., Kaygun, A., 2012c, Karaburun Yarımadası kuzey kıyılarının oșinografik özelliklerinin bentik foraminifer ve ostrakod toplulukları üzerindeki etkileri. M.T.A. Dergisi, 145, 2247, Ankara.

Meriç, E., Yokeș, M.B., Avșar, N., Bircan, C., 2012d, A new observation on abnormal development in benthic foraminifers: Peneroplis pertusus (Forskal)-Peneroplis planatus (Fichtel and Moll) togetherness. Anales de Biologia, 34, 43-48.

Meriç, E., Avșar, N., Nazik, A., Koçak, F., YücesoyEryılmaz, F., Eryılmaz, M., Barut, İ. F., Yokeș, M. B., Dinçer, F., Esenli, F., Esenli, V., Özdemir, Z., Türker, A., Aydın, Ș., 2012e, Edremit Körfezi (Balıkesir) kıyı alanlarında oșinografik özellliklerin bentik foraminifer, ostrakod ve bryozoon toplulukları üzerindeki etkileri ile ilgili yeni veriler. T.P.J.D. Bülteni, 24 (2), 31-77, Ankara. 
Meriç, E., Avșar, N., Barut, İ. F., Eryılmaz, M., Yücesoy-Eryılmaz, F., Yokeș, B., Dinçer, F., 2014, Edremit Körfezi ve Dikili Kanalı (KD Ege Denizi) kıyı alanlarında jeolojik yapı özeliklilerinin belirlenmesinde bentik foraminiferlerin önemi. M.T.A. Dergisi, 148, 61-67, Ankara.

Meriç, E., Avșar, N., Nazik, A., Yokeș, B., Barut, I. F., Suner, F., Sarı, E., Eryılmaz, M., YücesoyEryılmaz, F., Dora. Ö., Kam, E., Dinçer, F., 2017, A multi disciplinary overview of factors controlling on meiofauna assemblages around Maden and Alibey islands in Ayvalik (Balikesir, Eastern Aegean Sea). Journal of African Earth Sciences, 129, 558-578.

Meriç, E., Barut, i. F., Nazik, A., Avșar, N., Yokeș, M. B., Eryılmaz, M., Yücesoy-Eryılmaz, F., Kam, E., Sonuvar, B., Dinçer, F., 2018a, Doğanbey Burnu (Seferihisar-Izmir) denizdibi termalsu kaynaklarının foraminifer, ostrakod ve mollusk topluluğuna etkisi. MTA Dergisi, 156, 89-118, Ankara.

Meriç, E., Nazik, A., Yokeș, M. B., Barut, I. F., Kumral, M., Eryılmaz, M., Yücesoy-Eryılmaz, M., Sonuvar, B., Dinçer, F., 2018b, Aliağa (İzmir) sıcak ve soğuk su çıkııları çevresinde meiobentik yașam: foraminifer, ostrakod ve mollusk toplulukları.Türkiye Jeoloji Bülteni (yayın așamasında).

Miller, A. M., 1972. Speculations Concerning Bottom Circulation in the Mediterranean Sea. The Mediterrenean Sea: A Natural Sedimentation Laboratory (ed. D.J. Stanley), Dowden Hutchinson \& Ross, Inc., 37-42, ISBN: 0-87933-010-4, Stroudsburg.

Papadopoulos V., Spyropoulos K., Georgopoulos D. and Feredinos G., 2009. Current Observations in the North Aegean Sea. 9th Symposium On Oceanography \& Fisheries, (13-16 May), Proceedings, Volume 1, 445-449, Patras, Greece.

Politikos,D.V., loakeimidis, C., Papatheodorou, G. and Tsiaras, K., 2017. Modeling the Fate and Distribution of Floating Litter Particles in the Aegean Sea (E. Mediterranean). Frontiers in Marine Science. Vol. 4, Article 191, 1-18,, doi: 10.3389/fmars.2017.00191.

Poulos, S.E., Drakopoulos P.G. and Collins, M.B., 1997. Seasonal Variability in Sea Surface
Oceanographic Conditions in the Aegean Sea (Eastern Mediterranean): An Overview. Journal of Marine Systems, Vol. 13, Issues 1-4, 225-244, doi.org/10.1016/S09247963(96)00113-3.

Șengör, A. M. C., Görür, N., Șaroğlu, F., 1985, Strikeslip faulting and related basin formation in zones of tectonic escape: Turkey as a case study . In: Biddle, K. T. and Christi-Blick, N. (Eds.), Strike-slip deformation. Society of Economic Paleontologists and Mineralogists special publication 37, 227-264.

Triantaphyllou, M. V., Koukousioura, O., Dimiza, M. D., 2009, The presence of the Indo-Pacific symbiont-bearing foraminifer Amphistegina lobifera in Greek coastal ecosystems (Aegean Sea, Eastern Mediterranean). Mediterranean Marine Science, 10 (2), 73-85.

Triantaphyllou, M. V., Dimiza, M. D., Koukousioura, O., Hallock, P., 2012, Observations of the life cycle of the Symbion-bearing foraminifer Amphistegina lobifera Larsen, an invasive species in coastal ecosystem of the Aegean Sea (Greece-E. Mediterranean). Jouurnal of Foraminiferal Research, 42 (2), 143-150.

Yokeș, M. B., Meriç, E., Avșar, N., Barut, I. F., Taș, S., Eryılmaz, M., Dinçer, F., Bircan, C., 2014, Opinion and comments on the benthic foraminiferal assemblages observed around the mineral submarine springs in Kușadası (Aydin-Turkey). Marine Biological Association of the United Kingdom, 1-17, doi:10.1017/ S1755267214000840, vol. 7, e103; 2014, published on line.

Yücesoy-Eryılmaz F. ve Eryılmaz M., 2002; Kuzeydoğu Ege Denizi Ve Marmara Denizi Geçiș Bölgesi Çökellerinde İnce Tane Boyunun Ağır Metal Dağılımına Etkisi. Türkiye Jeoloji Bülteni. Cilt 45, Sayı 1, 111-124, Ankara.

Yücesoy-Eryılmaz, F., Eryılmaz, M., Esenli, F., Esenli, V., Özdemir, Z., Türker, A. ve Aydın, Ș., 2005. Edremit Körfezi Ve Dikili Kanalı Güncel Çökellerinin Sedimantolojisi Ve Jeokimyası; TÜBITAK Destekli, Proje No YDABCAG 100Y098, 152 Sayfa, Mersin.

Zeri, C., Beșiktepe, T., Giannakourou, A., Krasakopoulou, E., Tzortziou, M., Tsoliakos, D., Pavlidou, A., Mousdis, G., Pitta, E., Scoullos, 
M. and Papathanassiou, E., 2014, Chemical Properties and Fluorescence Of DOM in Relation to Biodegradation in the Interconnected Marmara-North Aegean Seas During August 2008. Journal of Marine Systems, 135, 124-136, DOI: 10.1016/j. jmarsys.2013.11.019.

Zmiri, A., Kahan, D., Hochstein, S., Reis, Z., 1974, Phototaxis and thermotaxis in some species of Amphistegina (Foraminifera). Journal of Protozoology, 21, 133-138.
Zodiatis, G., Alexandri, S., Pavlakis, P., Jonsson, L., Kallos, G., Demetropoulos, A., Georgiou, G., Theodorou, A. and Balopoulos, E., 1996, Tentative study of flow patterns in the North Aegean Sea using NOAA-AVHRR images and 2D model simulation Anneles Geophysicae 14, 1221-1231. 
